\title{
Prevalence of chronic bronchitis in Rhodesian Africans
}

\author{
J. B. COOKSON ${ }^{1}$ AND G. MATAKA
}

From The Department of Medicine, University of Rhodesia, PO Box ST494, Southerton, Salisbury, Rhodesia

Cookson, J. B., and Mataka, G. (1978). Thorax, 33, 328-334. Prevalence of chronic bronchitis in Rhodesian Africans. The prevalence of chronic bronchitis in the African population of a small township in Rhodesia was estimated using two questionnaires, both based on those of the British Medical Research Council. The first, a screening questionnaire, was put to 9768 subjects aged 5 years and above and the second, a more detailed questionnaire, to random selections of these grouped according to their replies. Repeat interviews were used to assess the accuracy of the questionnaires. The overall prevalence of chronic bronchitis was $1 \cdot 12 \%$. This is much lower than most other surveys elsewhere. There was little evidence of an increase in prevalence with age, and rates were not significantly different in the two sexes. The prevalence of complications and of other chest symptoms was correspondingly low. The proportion of bronchitics who smoked was not significantly higher than in the controls. Amounts smoked, however, were generally much lower than in other populations, and this, together with low levels of pollution, probably account for the prevalence findings.

Chronic bronchitis is probably the most important pulmonary disease in the Western world, and the formulation of a definition (Ciba Foundation, 1959) and the adoption of the standardised questionnaires developed by the Medical Research Council (1960) has allowed comparison of its prevalence in many different countries.

Among developing countries, surveys have been performed in India (Joshi et al., 1975), Papua New Guinea (Anderson, 1976), and in the Caribbean (Miller and Ashcroft, 1971), but there is very little information about the prevalence of this disease in Africa. Paul (1961) in Northen Rhodesia (now Zambia) asked a large number of male miners and non-miners 'whether or not they had a persistent cough with sputum', and Sluis-Cremer (personal communication) has surveyed certain occupational groups in South Africa with the MRC questionnaire.

To discover more about the importance of this disease in Africa, we have surveyed a total community using a modified MRC questionnaire and compared our findings with similar surveys else-

'Present address: Groby Road Hospital, Groby Road, Leicester, UK where. The survey was also designed to determine the prevalance of asthma, but this report is confined to chronic bronchitis.

\section{Methods}

The population chosen was that of the main African suburb of Gatooma, a small town 80 miles $(130 \mathrm{~km})$ from Salisbury. This population is of moderate size, lives in a circumscribed area, and $\frac{7}{0}$ is reasonably representative of African urban society. The town had the disadvantage of being $N$ the centre of Rhodesia's cotton industry so care N was necessary to record occupation. It is sur- $N$ rounded by farm land, and there are no important $\omega$ sources of pollution. The midday temperature for most of the year averages $25-30^{\circ} \mathrm{C}$. During the short winter (May-July) night temperatures fall to near freezing, but the days remain warm.

QUESTIONNAIRES

Two questionnaires were used. The first was given $\frac{\Omega}{\square}$ to as many people as possible aged 5 years and $\varrho$ over and the second to a random selection of these according to the methods described below. 
Both were based on the MRC (1966) questionnaire. The first (termed the short) questionnaire asked 11 screening questions about cough either first thing in the morning, or during the day, or at night, both in summer and winter; about sputum production; about shortness of breath when walking either on the level or up a slight hill; and about shortness of breath with wheezing either currently or in the past. The second and long questionnaire repeated the first and asked additional questions about duration of symptoms, chest illness, smoking, residence, and occupation. The short questionnaire attempted to identify all those with chest symptoms while the long was designed to identify chronic bronchitics. Translation was performed by the Department of African Languages of the University of Rhodesia. The results were shown to several African hospital interpreters, nursing sisters, and medical students, who suggested certain modifications to improve comprehension by persons with a limited education.

The short questionnaire was distributed by finding one member of each household and giving him enough forms for the whole family. The forms were filled in that night and returned the next day. Individuals were contacted through schools, places of work, and house visits. When explaining the project the importance of everybody (including perfectly fit persons) completing a form was stressed. Community leaders were approached first so that they would understand the nature of the project and could reassure others if asked.

As there was no clear pattern of positive replies to the short questionnaire, the 11 questions were combined into five groups; winter cough, summer cough, sputum production, shortness of breath, and wheezy breathlessness. A random sample was then taken from each combination of these groups (using random sampling numbers), taking higher percentages from those containing more symptoms. A control sample was also taken from those replying 'No' to all questions. As the first random selection from the 'Yes' group did not, in the event, provide enough chronic bronchitics for analysis, a further sample was taken later.

The long questionnaire was applied to all those selected in this way unless a subject refused or could not be traced when a substitute, if available, was taken from the same group. This questionnaire was administered by a single interviewer trained in the technique. He was a resident of the township, a trained laboratory assistant, and had previously conducted prevalence surveys in this township. The MRC's instructions on the use of the questionnaire were followed so far as they were applicable.

If replies to the questionnaires contradicted each other this was pointed out to the subject, who was then asked to choose the true state of affairs. He was not shown his replies to the short questionnaire before answering the long one.

\section{DEFINITIONS}

Chronic bronchitis was defined as a productive cough on most days for as much as three months each year. The MRC's questionnaire does not ask about duration in years because this is almost always for at least two years. This assumption could not be made in our study so an extra question was inserted, which showed that almost all subjects had indeed had symptoms for two years or more, so replies to this were ignored and conformity maintained with the MRC questionnaire. Subjects who also had variable wheezy breathlessness were considered to be asthmatic and were not included in the analysis.

A household member was any individual sleeping in that house on the night that it was surveyed.

A cigarette smoker was one who smoked at least one cigarette a day for as long as one year.

\section{VALIDATION}

Direct supervision of the interviewer was found not to be practicable, partly because of language difficulties and partly because the presence of an outsider was found to inhibit the procedure. $\mathrm{Re}$ liance was therefore first placed on detailed discussions with the interviewer both before and at intervals during the interviewing period. An African medical student, attached to the project for part of the time, was able to confirm that interviews were carried out consistently and correctly.

A further assessment was made by one of us (JBC), who re-interviewed and examined as many of those identified as chronic bronchitics as possible. This could not be an exact check as the subjects might change their minds, but it was considered that it would identify gross errors. Some discrepancies were found (described below), which were allowed for in the prevalence calculations.

\section{LUNG FUNCTION TESTING}

At this re-interview lung function testing was performed using a Godart 6-litre water spirometer to measure vital capacity (VC) and forced expiratory volume in $1 \mathrm{sec}\left(\mathrm{FEV}_{1}\right)$. Tests were administered by an African medical student trained in the technique. The procedure was explained to the sub- 
ject who then practised it until proficient. Three recordings of each measurement were made and the best selected. Height (without shoes) was measured in centimetres and weight (in indoor clothing) in kilograms. Results were converted to BTPS. An attempt was made to perform these tests on the controls but few attended. Results were therefore compared with prediction formulae for Rhodesian Africans (Cookson et al., 1976) drawn up in Salisbury.

\section{PREVALENCE CALCUlations}

The number of bronchitics identified by the long questionnaire was related to the group of the short questionnaire from which they were originally selected. Expected numbers were then calculated. The sum of these expressed as a percentage of the total population gave the overall prevalence rate.

Similar calculations were made to derive age specific prevalence rates and the prevalence of other symptoms elicited by the long questionnaire.

Significance testing was by the Chi-squared test using the fourfold table. $P$ values less than 0.05 were considered significant.

\section{Results}

All houses in the suburb were surveyed, but 38 were unoccupied. A total of 9768 persons were contacted with the short questionnaire, of whom 9287 completed it in full. Incomplete questionnaires were received from 99 , and $382(4 \%$ of the total) refused. Occasionally, however, the head of a household would refuse on behalf of his whole family. Since we had no means of knowing the size of that family, the true number of refusals is rather larger.

Of those who completed a short questionnaire, 6970 answered every question in the negative. They will be termed the 'No' group. Of these, 340 were selected to receive the long questionnaire and this was actually completed by 282 .

The remaining 2380 subjects replied 'Yes' to one or more questions. They will be termed the 'Yes' group. Of these, 941 were selected to receive the long questionnaire, and this was actually completed by 712 .

The age and sex distribution of the population was derived from all those replying to the short questionnaire and compared with figures for the African population of Rhodesia as a whole taken from census returns (Central Statistical Office) (Table 1). There are more young men in the suburb, presumably because of employment opportunities, but fewer children and old people.
Table 1 Age and sex distribution of the population surveyed compared with that of the African population of Rhodesia taken from census returns

\begin{tabular}{|c|c|c|c|c|c|c|}
\hline \multirow[b]{2}{*}{ Age } & \multicolumn{3}{|c|}{ Male subjects } & \multicolumn{3}{|c|}{ Female subjects } \\
\hline & No. & $\%$ & Census \% & No. & $\%$ & Census \% \\
\hline $\begin{array}{c}5-9 \\
10-14 \\
15-19 \\
20-24 \\
25-29 \\
30-34 \\
35-39 \\
40-44 \\
45-49 \\
50-54 \\
55-59 \\
\geqslant 60\end{array}$ & $\begin{array}{r}739 \\
837 \\
593 \\
513 \\
690 \\
618 \\
544 \\
370 \\
247 \\
143 \\
84 \\
100\end{array}$ & $\begin{array}{r}13.5 \\
15 \cdot 3 \\
10 \cdot 8 \\
9.4 \\
12.6 \\
11 \cdot 3 \\
9.9 \\
6.8 \\
4.5 \\
2.6 \\
1.5 \\
1.8\end{array}$ & $\begin{array}{r}20 \cdot 9 \\
16 \cdot 3 \\
12 \cdot 2 \\
8 \cdot 8 \\
8 \cdot 1 \\
7 \cdot 4 \\
6 \cdot 6 \\
5 \cdot 0 \\
4 \cdot 8 \\
3 \cdot 5 \\
2 \cdot 5 \\
3 \cdot 9\end{array}$ & $\begin{array}{r}763 \\
816 \\
551 \\
442 \\
387 \\
313 \\
210 \\
146 \\
90 \\
39 \\
17 \\
35\end{array}$ & $\begin{array}{r}20 \cdot 0 \\
21 \cdot 4 \\
14 \cdot 5 \\
11 \cdot 6 \\
10 \cdot 2 \\
8 \cdot 2 \\
5 \cdot 5 \\
3 \cdot 8 \\
2.4 \\
1 \cdot 0 \\
0.5 \\
0.9\end{array}$ & $\begin{array}{r}21 \cdot 3 \\
16 \cdot 5 \\
12 \cdot 4 \\
10 \cdot 8 \\
9 \cdot 1 \\
7 \cdot 5 \\
6 \cdot 4 \\
4 \cdot 4 \\
4 \cdot 2 \\
2 \cdot 5 \\
1 \cdot 7 \\
3 \cdot 2\end{array}$ \\
\hline Totals & 5478 & 100 & 100 & 3809 & 100 & 100 \\
\hline
\end{tabular}

Altogether 287 people, though selected for the second questionnaire, did not complete it. In 273 cases this was because the subject had moved away from home and could not be traced. Seven subjects had died, and seven refused. To assess if chest disease was a factor in this migration, the percentage who moved away in the 'Yes' group $(24 \%)$ was compared with that in the 'No' group $(17 \%)$, since presumably the latter move for reasons other than their health. This difference is $\mathbb{D}$ significant $\left(x^{2}=7.61, \quad P<0.01\right) \quad$ suggesting that $\underset{\vec{F}}{\overrightarrow{2}}$ those with disease do indeed move away. As indi- 윽 cated above, however, a second random selection was necessary in the 'Yes' group, and this allowed more time for the natural migration of subjects.

The long questionnaire identified 48 bronchitics, all from the 712 subjects in the 'Yes' group. Only two subjects of the 282 in the 'No' group changed 0 their minds and said that they did have symptoms. Many replying 'Yes' to the short questionnaire $\delta$ replied 'No' to the long, almost always because they had recorded mild transient symptoms on the $\mathrm{o}$ first occasion. Thirty-six of these bronchitics were re-interviewed, 33 giving a history consistent with the long questionnaire. One claimed no symptoms, and two were considered to be asthmatic. Num- $\sigma$ bers were modified appropriately, and a correction $N$ factor applied to those not re-interviewed. N

The prevalence rate for the whole population, calculated from these figures by the methods described above, was $1.12 \%$. The prevalence in all those aged over 20 was $1 \cdot 15 \%$ for men and $2.78 \% \stackrel{Ð}{+}$ for women, and in those aged 40 and above $1.54 \%$ for men and $5.60 \%$ for women. Small numbers made further division by age not worthwhile and $\vec{\Phi}$ also meant that the greater prevalence among $\stackrel{\odot}{\Phi}$ women was not significant in either group (over $\cong$ $20, x^{2}=2 \cdot 75, \mathrm{P}<0.10 ;$ over $\left.40, x^{2}=0.13, \mathrm{P}<0.7\right)$. Table 2 shows the prevalence of certain other 
Table 2 Prevalence of respiratory symptoms by age

\begin{tabular}{|c|c|c|c|c|c|c|c|c|c|c|c|c|}
\hline \multirow[b]{2}{*}{ Symptoms } & \multicolumn{2}{|c|}{ Age 5-14 } & \multicolumn{2}{|c|}{$15-24$} & \multicolumn{2}{|c|}{$25-34$} & \multicolumn{2}{|c|}{$35-44$} & \multicolumn{2}{|c|}{$45-54$} & \multicolumn{2}{|c|}{$\geqslant 55$} \\
\hline & No. & $\%$ & No. & $\%$ & No. & $\%$ & No. & $\%$ & No. & $\%$ & No. & $\%$ \\
\hline \multicolumn{13}{|l|}{ Males } \\
\hline Winter cough & 23 & $5 \cdot 6$ & 28 & $8 \cdot 2$ & 28 & $8 \cdot 6$ & 26 & 6.9 & 18 & $10 \cdot 9$ & 7 & $11 \cdot 4$ \\
\hline Prolonged* winter cough & 16 & $2 \cdot 8$ & 12 & 1.9 & 14 & $3 \cdot 3$ & 17 & $3 \cdot 3$ & 13 & $5 \cdot 6$ & 7 & $11 \cdot 4$ \\
\hline Summer cough & 14 & $2 \cdot 7$ & 20 & $4 \cdot 8$ & 26 & $5 \cdot 5$ & 25 & $4 \cdot 6$ & 20 & $9 \cdot 9$ & 7 & $11 \cdot 4$ \\
\hline Prolonged* summer cough & 9 & $1 \cdot 6$ & 10 & $1 \cdot 6$ & 14 & $3 \cdot 1$ & 13 & $2 \cdot 7$ & 14 & $7 \cdot 3$ & 3 & $3 \cdot 4$ \\
\hline Winter and/or summer cough & 24 & $5 \cdot 8$ & 32 & $9 \cdot 7$ & 31 & $9 \cdot 1$ & 28 & $7 \cdot 6$ & 19 & 11.2 & 8 & $12 \cdot 0$ \\
\hline Any sputum production & 21 & $3 \cdot 9$ & 26 & $8 \cdot 4$ & 32 & $7 \cdot 4$ & 26 & $6 \cdot 6$ & 19 & 9.1 & 8 & $7 \cdot 6$ \\
\hline Winter sputum 'usually' & 16 & $2 \cdot 1$ & 24 & $6 \cdot 7$ & 22 & $4 \cdot 5$ & 23 & $5 \cdot 3$ & 16 & 7.4 & 7 & $6 \cdot 5$ \\
\hline 'Severe' $\dagger$ dyspnoea & 2 & 0.4 & 4 & 0.7 & 9 & $2 \cdot 2$ & 9 & $3 \cdot 6$ & 7 & 3.3 & 3 & $2 \cdot 6$ \\
\hline \multicolumn{13}{|l|}{ Females } \\
\hline Winter cough & 30 & $6 \cdot 7$ & 19 & $6 \cdot 4$ & 15 & $6 \cdot 7$ & 12 & $11 \cdot 4$ & 4 & $8 \cdot 1$ & 3 & $40 \cdot 4$ \\
\hline Prolonged* winter cough & 22 & $4 \cdot 6$ & 10 & $2 \cdot 5$ & 13 & $3 \cdot 7$ & 10 & $7 \cdot 0$ & 3 & $4 \cdot 4$ & 2 & $22 \cdot 1$ \\
\hline Summer cough & 27 & $4 \cdot 7$ & 18 & $5 \cdot 6$ & 19 & $5 \cdot 8$ & 11 & $7 \cdot 5$ & 4 & $6 \cdot 1$ & 2 & $21 \cdot 2$ \\
\hline Prolonged* summer cough & 16 & $1 \cdot 7$ & 8 & $2 \cdot 4$ & 12 & $3 \cdot 5$ & 8 & $6 \cdot 0$ & 2 & $2 \cdot 4$ & $\overline{1}$ & $2 \cdot 9$ \\
\hline Winter and/or summer cough & 31 & $7 \cdot 1$ & 23 & $7 \cdot 3$ & 20 & $8 \cdot 4$ & 16 & $11 \cdot 6$ & 5 & $9 \cdot 8$ & 3 & $40 \cdot 4$ \\
\hline Any sputum production & 27 & $4 \cdot 7$ & 17 & $5 \cdot 1$ & 17 & $7 \cdot 6$ & 11 & $6 \cdot 3$ & 5 & $9 \cdot 7$ & 3 & $40 \cdot 0$ \\
\hline Winter sputum 'usually' & 24 & $4 \cdot 5$ & 14 & $4 \cdot 5$ & 15 & $7 \cdot 1$ & 11 & $4 \cdot 6$ & 4 & $8 \cdot 0$ & 3 & $40 \cdot 0$ \\
\hline 'Severe' $\dagger$ dyspnoea & 6 & 0.4 & 8 & $2 \cdot 2$ & 9 & $2 \cdot 4$ & 8 & $4 \cdot 7$ & 2 & $4 \cdot 0$ & 1 & $2 \cdot 9$ \\
\hline
\end{tabular}

*On most days for as much as 3 months each year. †Stops for breath when walking at own pace on the level.

respiratory symptoms by age in male and female subjects. Symptoms are included regardless of the presence or absence of others; thus those with sputum production include those with chronic bronchitis. It will be seen that summer cough is much less common than winter cough and that the combination of winter and summer cough is only slightly higher than winter cough alone. This suggests that those who cough in the summer also cough in the winter and that there are not two syndromes, summer cough and winter cough. The combination cough and sputum does not appear as all those with sputum production also admitted to cough. There were too few subjects to calculate age-specific prevalence rates for chest illnesses (increased cough and sputum lasting three weeks or more in the past three years) or for moderate dyspnoea (shortness of breath when walking with other people of own age on the level). Of the 34 adult bronchitics, 12 had chest illnesses, five had moderate or severe dyspnoea, and three had both.
Table 3 shows the smoking habits of male bronchitics and control subjects aged 15 years and over. No subject smoked more than 25 cigarettes a day. There were no pipe smokers and no ex-smokers. The proportion of bronchitics who smoked $(47 \%)$ was not significantly greater than for the controls $(36 \%)\left(\chi^{2}=0.59, p<0.5\right)$. Only four women smoked-three controls and one bronchitic. The average age of onset of smoking was about 25 years.

Nine of the 15 male bronchitics who were reinterviewed and 56 of the 104 male control subjects, who were aged 20 years and over, had worked in a cotton factory. This difference is not significant $\left(\chi^{2}=0.03, p<0.9\right)$. No women worked in these factories. There were no miners or exminers among the bronchitics.

Two men and one woman with bronchitis had an $\mathrm{FEV}_{1}$ two SD below predicted normal values (Cookson et al., 1976), and in two of these the $\mathrm{FEV}_{1} \%$ was below 60 .

Table 3 Smoking habits of male bronchitics and controls aged 15 and over

\begin{tabular}{|c|c|c|c|c|c|c|}
\hline & Age 15-29 & $30-39$ & $40-49$ & $50-59$ & $\geqslant 60$ & Total \\
\hline \multirow{2}{*}{$\begin{array}{l}\text { Male bronchitics } \\
\text { Non-smoker } \\
\text { Cigarette smoker } \\
1-14 / \text { day } \\
15-29 / \text { day }\end{array}$} & 2 & 4 & 3 & & 1 & 10 \\
\hline & 4 & 2 & & 2 & 1 & 9 \\
\hline Total & 6 & 6 & 3 & 2 & 2 & 19 \\
\hline $\begin{array}{l}\text { Controls } \\
\text { Non-smoker } \\
\text { Cigarette smoker }\end{array}$ & 24 & 16 & 13 & 12 & 7 & 72 \\
\hline $\begin{array}{l}\text { 1-14/day } \\
15-29 / \text { day }\end{array}$ & 10 & 7 & $\begin{array}{r}10 \\
1\end{array}$ & 10 & 3 & $\begin{array}{r}40 \\
1\end{array}$ \\
\hline Total & 34 & 23 & 24 & 22 & 10 & 113 \\
\hline
\end{tabular}




\section{Discussion}

The two-stage technique used in this study enabled large numbers of subjects to be surveyed in a reasonable time at reasonable cost. Both selfadministered and interview methods were used. Interviews are more usual, but three studies (McNab et al., 1966; Pearl et al., 1966; Lebowitz and Burrows, 1976) have used self-administered questionnaires with success. The interview technique is important, it being particularly necessary to keep to an agreed protocol and to establish criteria for a positive reply (Fletcher, 1956; Fairbairn et al., 1959). In the present survey these points were met partly by detailed discussion before and during the interviewing period but mainly by re-interview of as many subjects with disease as possible. Surveys (McNab et al., 1966; Pearl et al., 1966) using a two-stage technique have found good correlations between the two questionnaires, but we found many fewer symptoms were reported on the long questionnaire. However only two subjects reported symptoms on this questionnaire but not on the first; thus the aim of the short questionnaire, to identify all those with chest symptoms, seems to have been largely achieved.

Questionnaires were kept as close as possible to that of the MRC for comparison with other surveys. The MRC questionnaires have been translated into many languages, but this was the first African one. This study confirmed Mork's (1964) view that translation should be performed not only by professional translators but also by those familiar with local medical idioms. Illiteracy was a possible problem but it appeared that those with a child at school had no difficulty and that others had a neighbour who customarily helped with such problems. Questionnaires are not yet a feature of daily life to the Rhodesian African and it was uncertain whether one would be acceptable at all. In fact the method seemed readily accepted by, and appropriate for, this population.

The definition used conformed to that of the Ciba Foundation (1959) symposium. No further requirement that dyspnoea or chest illness be part of the definition was made, although the questionnaire allowed for the calculation of both of these. The MRC proposal (1965) that a category of 'chronic mucopurulent bronchitis' be distinguished was not followed as collection and recording of sputum samples would have greatly complicated the organisation of the survey and would probably have reduced patient co-operation. Lung function testing, however, allowed calculation of the MRC's category of 'chronic obstructive bronchitis'. Definitions of chronic bronchitis exclude the presence of localised lung disease -0 such as bronchiectasis, the collagen diseases and pulmonary fibrosis, the pneumoconioses, primary cardiovascular-renal diseases, diseases of the chest $\not$ wall, and psychoneuroses (Ciba Foundation, 1959) These are not usually formally excluded in surveys as their prevalence is thought to be too low to affect the overall conclusions. It was not certain $\vec{\omega}$ that this would be true in Rhodesia, but radie ography was not possible because of cost and lack of equipment. Clinical examination, howeverw would probably have identified most patients with these diseases.

Refusals are a difficult problem in this typeo of survey since such subjects may have a differen? pattern of disease than the remainder (Andersonet al., 1963). The $4 \%$ refusal rate in this survescompares with rates varying from 0.84 to $25 \%$ in other large surveys (Fletcher and Tinker, 1961 $\overrightarrow{\mathrm{i}}$ Anderson et al., 1965a). The low refusal rate fort the second questionnaire (seven subjects) was very satisfactory. A serious problem was the large migration rate that occurred between the two questionnaires. In particular, the apparentlo higher rate in the 'Yes' group might be due tळ disabled persons returning home. The need t\& perform a further selection from this group prob $\vec{\circ}$ ably explains this discrepancy however, althougl it is not possible to be certain. The low prevalence of bronchitis makes it unlikely that many returp home because of chest disability.

To compare this study with others requires the use of age-standardised rates to avoid distortion\& due to differences in age structure. Table 4 coms pares rates in Gatooma with those in similar sur: veys elsewhere. Populations were standardised to that of Gatooma. It will be seen that the rates in Gatooma are very much lower than most surveyso Many early studies were confined to those age $\$$ 40 and over but there were too few bronchitics io Gatooma to make meaningful comparisons in this్ age group alone.

There was no indication of a dramatic increas $\tilde{E}$ with age, although this has been a feature of some British surveys (Higgins, 1957; College of General Practitioners, 1961; Reid et al., 1974) The paucity of older subjects means that an such increase would not produce as many bron ${ }^{\circ}$ chitics as expected. This might partly explain the low prevalence in Gatooma but would not affeces the international comparisons. Unlike this suro vey, all others have shown a pronounced mas predominance.

The low rates in Gatooma are in keeping with other studies in Africa. A survey (Paul, 1961) i 
Table 4 Age-standardised prevalence rates of chronic bronchitis in Gatooma and in certain other similar surveys

\begin{tabular}{|c|c|c|c|c|c|}
\hline \multirow[t]{2}{*}{ Area } & \multirow[t]{2}{*}{ Age range } & \multirow[t]{2}{*}{ No. surveyed } & \multicolumn{2}{|c|}{ Prevalence } & \multirow[t]{2}{*}{ Reference } \\
\hline & & & Males & Females & \\
\hline $\begin{array}{l}\text { Gatooma } \\
\text { Vale of Glamorgan, UK } \\
\text { Berlin, New } \\
\text { Hampshire, USA }\end{array}$ & $\begin{array}{l}20+ \\
25-74 \\
25-74\end{array}$ & $\begin{array}{r}4994 \\
581 \\
1139\end{array}$ & $\begin{array}{r}1 \cdot 2 \\
13 \cdot 9 \\
23 \cdot 4\end{array}$ & $\begin{array}{r}2 \cdot 8 \\
10 \cdot 1 \\
8 \cdot 8\end{array}$ & $\begin{array}{l}\text { This study } \\
\text { Higgins (1957) } \\
\text { Ferris and Anderson } \\
\quad(1962)\end{array}$ \\
\hline $\begin{array}{l}\text { Tecumseh, Michigan, } \\
\text { USA }\end{array}$ & $20-79$ & 4542 & $7 \cdot 2$ & $3 \cdot 4$ & $\begin{array}{l}\text { Payne and Kjelsberg } \\
\text { (1964) }\end{array}$ \\
\hline $\begin{array}{l}\text { Glenwood Springs, } \\
\text { California, USA }\end{array}$ & $20-69$ & 609 & $17 \cdot 3$ & $12 \cdot 4$ & Mueller et al. (1971) \\
\hline $\begin{array}{l}\text { Chilliwack, British } \\
\text { Columbia, Canada }\end{array}$ & $25-74$ & 557 & $20 \cdot 7$ & $12 \cdot 9$ & Anderson et al. (1965b) \\
\hline Uppsala, Sweden & $30-64$ & 41679 & $2 \cdot 2$ & $1 \cdot 5$ & $\begin{array}{l}\text { Irnell and Kiviloog } \\
\text { (1968) }\end{array}$ \\
\hline Geneva, Switzerland & $20-60+$ & 1736 & $4 \cdot 5$ & 0.5 & $\begin{array}{l}\text { Rufener-Press et al. } \\
\text { (1973) }\end{array}$ \\
\hline $\begin{array}{l}\text { Busselton, } \\
\text { W. Australia }\end{array}$ & $20-74+$ & 3331 & $6 \cdot 3$ & $2 \cdot 4$ & Cullen et al. (1968) \\
\hline North India & $15-64$ & 473 & $12 \cdot 7$ & 一 & Joshi et al. (1975) \\
\hline
\end{tabular}

Northern Rhodesia (now Zambia) found that $0.1 \%$ of 3536 miners and none of 1815 non-miners had 'persistent cough with sputum'. Sluis-Cremer (personal communication) in Johannesburg, South Africa, found a prevalence of $7.8 \%$ in male nonminers over the age of 35 . They are also compatible with the low mortality figures recorded for Africans in Rhodesia (Rhodesia: Report of the Secretary for Health, 1975) and the rarity of necropsy evidence of emphysema found in Uganda (Jones and Madda, 1974). A genetic factor may be implicated as US negroes seem to have less bronchitis than whites (Murphy et al., 1962; Coates et al., 1965) and those of African descent living in the West Indies have less than those of Indian descent (Miller and Ashcroft, 1971). In Papua New Guinea Anderson (1976) has found a high prevalence of respiratory symptoms and signs with smoking playing a significant part. Methods are too different however to allow closer comparisons.

A striking feature of the Gatooma males was that although about $40 \%$ smoked, the bronchitics did not smoke significantly more than those without symptoms. This is in contrast to all other work in this field, which has shown a close relationship with smoking. Larger numbers might have shown a correlation, but an alternative explanation is that the Gatooma subjects did not smoke sufficiently to cause an effect, almost all smoking less than 15 cigarettes a day. In addition, the average age of starting smoking was 25 years. Surveys in Britain and North America of the smoking habits of whole populations have shown much higher levels and an earlier start. Fletcher and Tinker (1961) in Britain found that $43 \%$ smoked between one and 14 cigarettes a day and
$32 \%$ smoked more. Comparable figures by Holland and Stone (1965) in the USA were 9.6\% and $61.9 \%$. Smoking between one and 14 cigarettes a day seems to lead to only modest increases in bronchitis prevalence (Higgins et al., 1956; Higgins, 1957; Coates et al., 1965). The conclusion that smoking these amounts has little influence on bronchitis rates in Gatooma is supported by the findings in women, who have a similar prevalence to men but hardly smoke at all.

Pollution factors would appear unimportant in Gatooma, although no direct measurements have been made; neither could an important relationship to exposure to cotton dust be established.

We conclude that the prevalence of chronic bronchitis in this population is strikingly low. This may be due to a low consumption of cigarettes and low pollution levels.

We thank Mr. R. Mugweni and Dr. R. Mossop for help in organising and performing the survey. Mr. G. Makoni performed the lung function tests and Dr. W. Castle and Dr. G. Blake gave statistical advice. The study was supported by grants from the University of Rhodesia.

\section{References}

Anderson, D. O., Zickmantel, R., and Ferris, B. G. (1963). Response to a respiratory survey. Canadian Medical A ssociation Journal, 88, 596-602.

Anderson, D. O., Ferris, B. G., and Davis, T. W. (1965a). The Chilliwack respiratory survey. 1963. Canadian Medical Association Journal, 92, 899-905. Anderson, D. O., Ferris, B. G., and Zickmantel, R. (1965b). The Chilliwack respiratory survey. Canadian Medical Association Journal, 92, 10071016. 
Anderson, H. R. (1976). Respiratory abnormalities and ventilatory capacity in a Papua New Guinea Island community. American Review of Respiratory Disease, 114, 537-548.

Central Statistical Office (1969). Census of Population. Government Printer, Causeway, Salisbury, Rhodesia.

Ciba Foundation (1959). Terminology, definitions, and classification of chronic pulmonary emphysema and related conditions. Thorax, 14, 286-299.

Coates, E. O., Bower, G. C., and Reinstein, N. (1965). Chronic respiratory disease in postal employees. Journal of the American Medical Association, 191, 161-166.

College of General Practitioners (1961). Chronic bronchitis in Great Britain. British Medical Journal, 2, 973-979.

Cookson, J. B., Blake, G. T. W., and Faranisi, C. (1976). Normal values for ventilatory function in Rhodesian Africans. British Journal of Diseases of the Chest, 70, 107-111.

Cullen, K. J., Stenhouse, N. S., McCall, M. G., Welborn, T. A., and Curnow, D. H. (1968). Chronic respiratory disease in a rural community. Lancet, 2, 657-660.

Fairbairn, A. S., Wood, C. H., and Fletcher, C. M. (1959). Variability in answers to a questionnaire on respiratory symptoms. British Journal of Preventative and Social Medicine, 13, 175-193.

Ferris, B. G., and Anderson, D. O. (1962). The prevalence of chronic respiratory disease in a New Hampshire town. American Review of Respiratory Disease, 86, 165-177.

Fletcher, C. M. (1956). The epidemiological approach to chronic bronchitis. Transactions of the Association of Industrial Medical Officers, 6, 61-65.

Fletcher, C. M., and Tinker, C. M. (1961). Chronic bronchitis. British Medical Journal, 1, 1491-1498.

Higgins, I. T. T. (1957). Respiratory symptoms, bronchitis, and ventilatory capacity in random sample of an agricultural population. British Medical Journal, 2, 1198-1203.

Higgins, I. T. T.. Oldham, P. D., Cochrane, A. L., and Gilson, J. C. (1956). Respiratory symptoms and pulmonary disability in an industrial town. British Medical Journal, 2, 904-910.

Holland, W. W. , and Stone, R. W. (1965). Respiratory disorders in United States east coast telephone men. A merican Journal of Epidemiology, 82, 92-101.

Irnell, L., and Kiviloog, J. (1968). Bronchial asthma and chronic bronchitis in a Swedish urban and rural population. Scandinavian Journal of Respiratory Disease (Supplement), no. 66, 1-86.

Jones, A. W., and Madda, P. J. (1974). Necropsy incidence of emphysema in Uganda. Thorax, 29, 195-198.

Joshi, R. C., Madan, R. N., and Brash, A. A. (1975). Prevalence of chronic bronchitis in an industrial population in North India. Thorax, 30, 61-67.
Lebowitz, M. D., and Burrows, B. (1976). Compariso of questionnaires: the BMRC and NHLI respirao tory questionnaires and a new self-completiof questionnaire. American Review of Respirator Disease, 113, 627-635.

McNab, G. R., Slator, E. J., and Stewart, C. $\stackrel{\Phi}{\rho}$ (1966). Responses to a questionnaire on chroniक्ष bronchitic symptoms in East Anglia. British Journal of Preventative and Social Medicine, 20, 181 ㅡㄹ 188.

Medical Research Council (1960). Standardise questionaires on respiratory symptoms. Britis Medical Journal, 2, 1665.

Medical Research Council (1965). Definition and classification of chronic bronchitis. Lancet, 1, 775 779.

Miller, G. J., and Ashcroft, M. T. (1971). A compo munity survey of respiratory disease among East Indian and African adults in Guyana. Thorax, 26, 331-338.

Mork, T. (1964). International comparisons of the prevalence of chronic bronchitis. Proceedings of the Royal Society of Medicine, 57, 975-978.

Mueller, R. E., Keble, D. L., Plummer, J., and Walker, S. H. (1971). The prevalence of chronie bronchitis, chronic airway obstruction and respiras tory symptoms in a Colorado city. American $R$ es view of Respiratory Disease, 103, 209-228.

Murphy, R. E., Katz, S., Massaro, D. J., and Luch singer, P. C. (1962). Is emphysema a disease pre dominantly of the white male? Journal of the American Medical Association, 181, 726-727.

Paul, R. (1961). Chronic bronchitis in African miners and non-miners in Northern Rhodesia. Britis Journal of Diseases of the Chest, 55, 30-34.

Payne, M., and Kjelsberg, M. (1964). Respirator symptoms, lung function, and smoking habits in am adult population. American Journal of Puble Health, 54, 261-277.

Pearl, R. B., Levine, D. B., and Gerson, E. 承 (1966). Studies of disease among migrants and native populations in Great Britain, Norway, an the United States. National Cancer Institute Mon@ graph, 19, 301-320.

Reid, D. D., Hamilton, P. J. S., Keen, H., Bret G. Z., Jarrett, R. J., and Rose, G. (1974). CardiF. respiratory disease and diabetes among middle-agef male civil servants. Lancet, 1, 469-473.

Rhodesia. Report of the Secretary for Health, 1975 (1976). Government Printer, Causeway, Salisburt: Rhodesia.

Rufener-Press, C., Rey, P., and Press, P. (1973 Une étude épidémiologique de la bronchite chronique à Genève. Respiration, 30, 458-516.

Requests for reprints to: Dr. J. B. Cookson, Grob Road Hospital, Groby Road, Leicester, UK. 